\title{
Adenosine in the Thymus
}

\author{
Krisztina Köröskényi1,2, Gergely Joós ${ }^{1,2}$ and Zsuzsa Szondy1,2* \\ 1 Department of Biochemistry and Molecular Biology, Faculty of Medicine, University of Debrecen, Debrecen, Hungary, \\ ${ }^{2}$ Department of Basic Medical Sciences of Dental Faculty, University of Debrecen, Debrecen, Hungary
}

\section{OPEN ACCESS}

Edited by:

Kenneth A. Jacobson, National Institutes of Health $(\mathrm{N} / \mathrm{H})$, United States

Reviewed by: Celio Geraldo Freire De Lima, Universidade Federal do Rio de Janeiro, Brazi Philippe Saas,

INSERM UMR1098 Interactions Hôte-Greffon-Tumeur and Ingénierie Cellulaire et Génique, France

*Correspondence: Zsuzsa Szondy szondy@med.unideb.hu

Specialty section: This article was submitted to Experimental Pharmacology and Drug Discovery,

a section of the journal

Frontiers in Pharmacology

Received: 18 October 2017 Accepted: 11 December 2017 Published: 22 December 2017

Citation:

Köröskényi K, Joós G and Szondy Z (2017) Adenosine in the Thymus. Front. Pharmacol. 8:932. doi: 10.3389/fphar.2017.00932
Adenosine is an ancient extracellular signaling molecule that regulates various biological functions via activating four $G$-protein-coupled receptors, $A_{1}, A_{2 A}, A_{2 B}$, and $A_{3}$ adenosine receptors. As such, several studies have highlighted a role for adenosine signaling in affecting the $T$ cell development in the thymus. Recent studies indicate that adenosine is produced in the context of apoptotic thymocyte clearance. This review critically discusses the involvement of adenosine and its receptors in the complex interplay that exists between the developing thymocytes and the thymic macrophages which engulf the apoptotic cells. This crosstalk contributes to the effective and immunologically silent removal of apoptotic thymocytes, as well as affects the TCR-driven T-cell selection processes.

Keywords: efferocytosis, adenosine, thymocyte, apoptosis, T cell selection

\section{INTRODUCTION}

Generation of immunocompetent $\mathrm{T}$ lymphocytes from bone marrow-derived $\mathrm{CD} 4^{-} \mathrm{CD} 8^{-}$double negative progenitors takes place in the thymus. This process occurs through a series of differentiation and selection steps (Bommhardt et al., 2004) leading via apoptosis to the removal of 95\% of thymocytes produced with improper TCR. T-cell differentiation is unique in a sense that it is not a cell-autonomous process, but depends on signals provided by fibroblasts, thymic epithelial cells, macrophages, dendritic cells, and endothelial cells that surround the developing thymocytes (Petrie and Zuniga-Pflucker, 2007). Among these cells thymic epithelial cells play the major role in shaping the $\mathrm{T}$ cell repertoire by presenting self-antigens on their cell surface (Alexandropoulos and Danzi, 2012), while thymic F $4 / 80^{+}$macrophages are the main cleaners of the constantly produced dying cells (Surh and Sprent, 1994). While generally tissue resident macrophages are originated from the yolk sac (Gomez et al., 2015), part of the thymic macrophages seem to be differentiated from the hematopoietic stem cells (Haymaker et al., 2012) or even from T cell progenitors (Esashi et al., 2004) in the bone marrow.

At the beginning of differentiation, $\mathrm{CD} 4^{-} \mathrm{CD} 8^{-}$progenitor cells rearrange their TCR $\beta$ gene locus to produce a pre-TCR complex. Subsequently, thymocytes divide rapidly, become $\mathrm{CD} 4^{+} \mathrm{CD} 8^{+}$DP thymocytes, then they rearrange their TCR $\alpha$ chain as well. Those thymocytes, which successfully generate a functional $\alpha$ chain replace the pre-TCR with mature TCR $\alpha \beta$ and continue to differentiate $\mathrm{CD} 4^{+} \mathrm{CD} 8^{+} \mathrm{TCR} \alpha \beta^{\text {low }}$ cells (Hernandez et al., 2010). The TCR of these thymocytes is able to interact with self-peptides presented on major histocompatibility complex molecules of thymic non-lymphoid cells. Their destiny will be decided by the strength of the TCR $\alpha \beta$

Abbreviations: ADA, adenosine deaminase; ADO, adenosine; AR, adenosine receptor; $\mathrm{CO}$, carbon monoxide; DP, double positive; MAPK, mitogen-activated protein kinase; NPP, nucleotide pyrophosphatase/phosphodiesterase; NECA, $N$-ethylcarboxamidoadenosine; 8-PT, 8-phenyl-theophylline; $\mathrm{PGE}_{2}$, prostaglandin $\mathrm{E}_{2}$; TCR, T-cell receptor; TG2, transglutaminase 2 ; TGF- $\beta$, transforming growth factor- $\beta$; $\mathrm{T}_{\text {reg }}$, regulatory $\mathrm{T}$ cell; $\mathrm{t}_{\text {reg }}$, thymic regulatory $\mathrm{T}$ cell. 
signal generated during this interaction. Cells receiving a TCR $\alpha \beta$ signal of intermediate strength continue to differentiate into $\mathrm{CD}^{+}$or $\mathrm{CD}^{+}$TCR $\alpha \beta^{\text {high }}$ single positive thymocytes, leave the thymic cortex and complete their maturation in the thymic medulla, while those, which are exposed to a strong $\mathrm{TCR} \alpha \beta$ signal, are eliminated by activation-induced apoptosis, a major mechanism for generating self-tolerance (Kisielow and von Boehmer, 1995). A few percent of thymocytes that have TCR specificities for higher affinity ligands than that of the conventional CD4 ${ }^{+} \mathrm{T}$ cells (Moran et al., 2011) are diverted into $\mathrm{CD} 4{ }^{+} \mathrm{CD} 25^{+} \mathrm{FoxP}^{+} \mathrm{tT}_{\text {reg }}$, which induce peripheral tolerance by silencing excessive peripheral immune responses, thus prevent autoimmunity (Benoist and Mathis, 2012). The remaining 90\% of the DP thymocytes express TCRs, which cannot interact with peptide-loaded self-major histocompatibility molecules, thus in the absence of TCR-driven cell survival signals they undergo a default apoptosis cell death pathway named "death by neglect."

Increasing evidence indicate that molecules produced by macrophages during the constant engulfment of apoptotic cells generate a thymic milieu for the developing thymocytes that affect the TCR-determined cell selection processes. These molecules are produced primarily not to regulate thymic selection processes, rather they are needed for the macrophages themselves. Thus, in response to the chemotactic signals produced by dying thymocytes, macrophages release ATP that contributes to their migration to the apoptotic site (Kronlage et al., 2010). Following apoptotic cell phagocytosis, they release TGF- $\beta$ and prostaglandin $\mathrm{E}_{2}\left(\mathrm{PGE}_{2}\right)$ to prevent their pro-inflammatory cytokine production in an autocrine manner (Fadok et al., 1998). During degrading hem containing proteins, they also produce $\mathrm{CO}$ as a result of hem oxygenase-I action (Gemsa et al., 1973). And finally, macrophages also produce retinoids in an engulfment-dependent manner (Garabuczi et al., 2013) that regulate their own phagocytic capacity (Sarang et al., 2014). However, DP thymocytes express receptors for the macrophage-released molecules, such as ATP, PGE 2 , TGF$\beta$, CO or retinoids (Cillie et al., 1983; Suzuki et al., 1991; Szondy et al., 1997; Levéen et al., 2005; Tsukimoto et al., 2006; Dzhagalov et al., 2007), and respond to them with an outcome that depends on the simultaneous TCR signaling. Thus, all these molecules were shown to induce or enhance thymocyte death in the absence of TCR signaling (Szondy et al., 2012). Macrophage-derived retinoids and TGF- $\beta$ also synergize in the induction of TG2 (Fésüs and Szondy, 2005) in apoptotic thymocytes (Garabuczi et al., 2013). TG2 in dying cells contributes to the formation of a chemotactic signal for macrophage recruitment (Nishiura et al., 1998), prevents the leakage of the harmful cell content (Piredda et al., 1997) and facilitates the exposure of phosphatidylserine, the main important apoptotic cell recognition signal for macrophages (Sarang et al., 2007). On the other hand, in the presence of TCR signaling retinoids inhibit TCR-mediated cell death in a dose-dependent manner, thus regulate the threshold of negative selection (Szondy et al., 1998; Szegezdi et al., 2003; Sarang et al., 2013), while TGF- $\beta$ plays such a determining role in the formation of $\mathrm{t}_{\text {reg }}$ cells, that no $\mathrm{t}_{\text {reg }}$ cells can be detected in the thymus until apoptosis and the consequent engulfment-dependent TGF- $\beta$ production is induced (Liu et al., 2008; Konkel et al., 2014; Chen and Konkel, 2015).

The fact that adenosine is also produced in the thymus and affects thymic selection processes was discovered after it was found that ADA deficiency leads to adenosine accumulation and severe T cell deficiency (Apasov et al., 2000).

\section{ADENOSINE}

Adenosine is an intra- and extracellularly produced purine nucleoside, which concentration is strictly controlled due to its intense and diverse biological effects. Intracellularly, it can be produced by three main pathways: (a) decomposition of adenine nucleotides (ATP, ADP, AMP) by ATPases, ATPase and cellular $5^{\prime}$ nucleotidase (c5'-NT); (b) hydrolysis of S-Adenosyl-Lhomocysteine by its hydrolase; (c) phosphodiesterase-mediated degradation of cAMP (Park and Gupta, 2012). Intracellularly $\mathrm{ADO}$ can be converted to inosine by $\mathrm{ADA}$ and later on to uric acid (da Rocha Lapa et al., 2014). It also can be shifted back to the nucleotide pool in the form of AMP by ADO kinase (Ramakers et al., 2011). Finally, it can be transported to the extracellular space by specific transporters (Antonioli et al., 2014). The extracellular ADO concentration is lower than $1 \mu \mathrm{M}(30-200 \mathrm{nM})$ under physiological conditions, but it can reach extremely high levels $(>100 \mu \mathrm{M})$ during inflammation and hypoxia (Haskó and Cronstein, 2004). The waste majority of extracellular ADO is formed extracellularly from ATP, which is transported out from various cells via exocytosis, co-release or ion channels (Chen et al., 2013; Antonioli et al., 2014). Extracellular ATP then undergoes a two-step hydrolysis. The rate limiting step in extracellular ADO formation is catalyzed by either ecto-nucleoside triphosphate diphosphohydrolases, such as CD39 that phosphohydrolyses ATP, and less efficiently $\mathrm{ADP}$, in a $\mathrm{Ca}^{2+}$ - and $\mathrm{Mg}^{2+}$-dependent fashion, to yield AMP (Heine et al., 2001), or by members of the ecto-nucleotide pyrophosphatase/phosphodiesterase family, such as NPP1 and 3 , which are also located on the cell surface, but produce AMP directly (Stefan et al., 2006). AMP in turn, is rapidly degraded to ADO by soluble or membrane-bound ecto- $5^{\prime}$ nucleotidases, such as CD73 (da Rocha Lapa et al., 2014). The effect of extracellular ADO is terminated by the decomposition of ADO by ecto-ADA or by the uptake into the surrounding cells through equilibrative nucleoside transporters (Liu and Xia, 2015).

\section{THE DIFFERENT ADENOSINE RECEPTORS}

The regulatory effects of $\mathrm{ADO}$, are almost exclusively mediated by the activation of its plasma membrane-associated receptors (ADO receptors) (Fredholm et al., 2001) which are expressed in a cell type specific manner. All of the four ARs $\left(A_{1} R, A_{2 A} R\right.$, $A_{2 B} R, A_{3} R$ ) belong to the large family of seven-transmembrane receptors, also known as G-protein-coupled receptors (Fredholm et al., 2001). Physiological ADO levels activate $A_{1} R, A_{2 A} R$, and 
$A_{3} R$ receptor subtypes ( $K_{i}=100-300 \mathrm{nM}$ for human receptors). $A_{2 B} R s\left(K_{i}=15 \mu M\right.$ for human $\left.A_{2 B} R\right)$ are activated only during pathological conditions (e.g., hypoxia, inflammation) (Haskó et al., 2007; Eltzschig, 2009; Dubyak, 2012). The duration and magnitude of the ADO's effect are influenced by a number of processes including intra- and extracellular production of $\mathrm{ADO}$, transport, cellular uptake, degradation, receptor density, as well as the activity of receptors and signaling molecules (Eltzschig, 2009; Chen et al., 2013). In general, ARs affecting intracellular cAMP levels are involved in the regulation of a large scale of biological processes (Liu and Xia, 2015). In addition, all of the four ARs can activate different types of MAPKs (p38, ERK1/2, JNK) (Antonioli et al., 2014). Further AR downstream effectors include phospholipase $C$, ion channels, phosphoinositide 3-kinase and protein kinase $\mathrm{B}$, nitric oxide, reactive oxygen species, and lipid mediators (Liu and Xia, 2015). Like other G-protein-coupled receptors, ARs tend to form homoand heterodimers as well as oligomers (Chen et al., 2013). With the formation of such complexes, the range of signaling pathways and biological processes controlled by ARs is further broadened.

\section{ADENOSINE METABOLISM AND ADENOSINE RECEPTORS IN THE THYMUS}

Studies in our laboratory have found that neither macrophages nor apoptotic thymocytes produce detectable amount of ADO, if they are cultured alone, but ADO is produced during the apoptotic cell engulfment indicating that $\mathrm{ADO}$ is an additional molecule which appears in the thymic milieu in an engulfmentdependent manner (Köröskényi et al., 2011). Apoptotic cells release adenine nucleotides via pannexin channels (Chekeni et al., 2010; Yamaguchi et al., 2014), which open in a caspase-dependent manner (Sandilos et al., 2012). In addition, thymocytes release ATP also via a pannexin channel-independent manner, when they undergo secondary necrosis (Sándor et al., 2017). CD39 is constitutively expressed in the thymus and is associated primarily with macrophages and $\mathrm{t}_{\text {reg }}$ cells (Antonioli et al., 2013), while thymocytes express NPP1 (Petersen et al., 2007). Thus in the thymic cortex, where apoptotic thymocytes and macrophages are present in close proximity, both cell types can contribute to the extracellular degradation of ATP to AMP. In accordance, high amount of AMP was detected in the culture of dying thymocytes (Yamaguchi et al., 2014). However, while CD73 and prostatic acid phosphatase are expressed by macrophages (Eichin et al., 2015), in thymocytes CD73 expression is differentiation-dependent: it is virtually absent in cortical thymocytes, but becomes upregulated in the medullary ones (Resta et al., 1997, 1998). Thus in the thymic cortex, where the majority of improper thymocytes die, $\mathrm{ADO}$ formation must be fully dependent on the CD73 activity of macrophages. Indeed, in the context of dying thymocytes and engulfing macrophages $\mathrm{ADO}$ production was confirmed in vitro to be fully dependent on the CD73 activity of macrophages (Yamaguchi et al., 2014; Sándor et al., 2017). The endogenous CD73 activity of macrophages is so high in the thymus that even if CD73 expression is artificially upregulated in thymocytes,

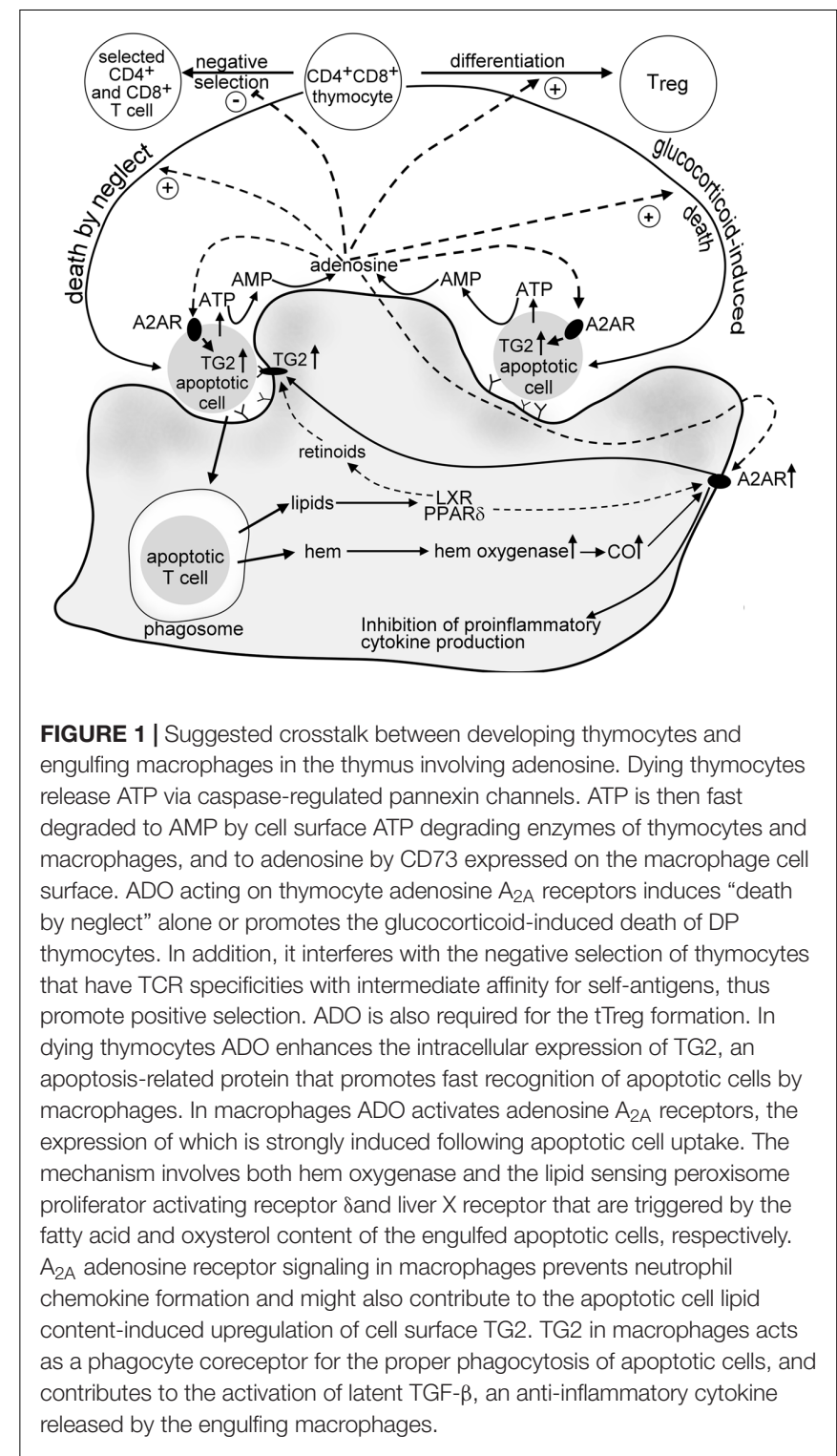

the in vivo thymic ADO levels do not change (Resta et al., 1997). The extracellular ADO concentrations in the thymus, however, are determined by the thymocyte ADA activities as well, and ADA activity was found to be extraordinarily high in cortical thymocytes, while to be strongly downregulated in the medullary ones (Chechik et al., 1981; Ma et al., 1982). These observations indicate that either ADO concentrations are kept lower in the cortical zone, where most of the positive selection takes place, while are higher in the medullary zone, where selected thymocytes mature further and also undergo negative selection. Alternatively, since in the medullary zone the rate of apoptosis, consequently the rate of ATP release is lower, thymocyte cell surface CD73 expression and the low thymocyte surface ADA activity together maintain the sufficient ADO levels around the thymocyte ARs. Loss of ADA activity in ADA deficient patients is associated with increased ADO levels in the thymus, which thus affect primarily the cortical 
thymocytes (Resta and Thompson, 1997). ADA, however, is responsible for the degradation of deoxyadenosine as well, thus low ADA activities in the cortex might promote formation of the intracellular dATP and consequently proliferation of cortical thymocytes (Sandberg, 1983). ARs are expressed already by the T-lymphopoietic and monocytopoietic cells as well, and both of them express all the four ARs. While, however, in the T-lymphopoietic lineage the expression of $\mathrm{A}_{2 \mathrm{~A}}$ Rs dominates, in the monocytopoietic cells all the $A_{2 A}, A_{2 B}$, and $A_{3}$ receptors are highly expressed subtypes (Streitová et al., 2010). However, as thymic apoptosis is initiated in the developing thymus and phagocytosis follows, engulfing macrophages upregulate their $\mathrm{A}_{2 \mathrm{~A}}$ Rs (Köröskényi et al., 2011), while downregulate the $\mathrm{A}_{3}$ ones (Duró et al., 2014). Upregulation of the $A_{2 A}$ Rs is engulfmentdependent in macrophages, and involves both lipid sensing transcription factors and CO produced via the hem oxygenase reaction (Haschemi et al., 2007; Köröskényi et al., 2011).

\section{EFFECT OF ADENOSINE ON THE T CELL DEVELOPMENT}

Early studies on fetal thymic organ cultures conducted in the presence of the ADO agonist $5^{\prime}$-( $N$-ethyl)carboxamidoadenosine, and the AR antagonist 8-phenyl-theophylline (8-PT) indicated that ARs influence the development of thymocytes, since administration of both compounds resulted in a decreased thymocyte cell number (Hamad, 1997). Results obtained with 8-PT were concluded in a way that $\mathrm{ADO}$ is required for proper thymocyte development, while results obtained with NECA indicated that higher concentrations of it induce thymocyte death. 8-PT is, however, not only an AR antagonist, but acts also as a potent inhibitor of cAMP phosphodiesterase. Thus, it can induce elevations in the intracellular cAMP levels (Nicholson and Wilke, 1989), and a consequent loss of thymocyte cell number due to cAMP-induced thymocyte death (McConkey et al., 1990). Thus 8-PT could decrease the thymocyte cell number by inducing apoptosis, rather than $\mathrm{ADO}$ being required generally for thymocyte differentiation. In accordance, loss of $\mathrm{A}_{2 \mathrm{~A}} \mathrm{Rs}$, the dominant thymocyte AR subtype, does not affect the number and the distribution of various thymocyte populations in mice (Kiss et al., 2006), despite of the fact that the expression of other ARs remained unchanged (Lukashev et al., 2003). ADO is, however, constantly produced in the cortical layer of the thymus, and can contribute to the apoptosis of neglected thymocytes similar to other signaling molecules that are also produced by macrophages in an engulfment-dependent manner (Szondy et al., 2012). The ADO-induced death of mouse thymocytes is strongly dependent on the $\mathrm{A}_{2 \mathrm{~A}} \mathrm{Rs}$, as in $\mathrm{A}_{2 \mathrm{~A}} \mathrm{R}$ null thymocytes ADO fails to induce significant cell death (Kiss et al., 2006). The ADO-dependent death in mouse thymocytes is mediated via cAMP and cAMP-dependent protein kinase (Armstrong et al., 2001; Kiss et al., 2006) and involves upregulation of Bim, a $\mathrm{BH} 3$-only pro-apoptotic member of the $\mathrm{Bcl}-2$ protein family (Kiss et al., 2006). In human thymocytes, on the other hand, ADO induces a $\mathrm{Ca}^{2+}$-dependent death (Szondy, 1994). ADO also promotes the glucocorticoid-induced death of neglected thymocytes (McConkey et al., 1993), and together with the engulfing macrophage-produced retinoids and TGF- $\beta$, also contributes to the upregulation of TG2 in the dying cells (Sándor et al., 2016, 2017). Thus, engulfing macrophage-produced apoptosis-promoting molecules, including $\mathrm{ADO}$, appearing in the cortical thymic milieu cooperate in both the fast killing of thymocytes, which express useless TCRs, and in the upregulation of their TG2 expression. These signals together are so crucial for the upregulation of TG2 in vivo that in vitro, though thymocytes die upon exposure to apoptotic stimuli, they cannot upregulate the expression of the protein (Szegezdi et al., 2000). Several molecules, which induce apoptosis of neglected thymocytes, also interfere with the TCR-mediated signaling pathways and inhibit negative selection in a dose dependent manner (Ashwell et al., 1996; Szondy et al., 1998; Szegezdi et al., 2003). For glucocorticoids, it has been demonstrated that this way these molecules determine the TCR avidity thresholds that determine whether developing thymocytes survive or die, and therefore help to mold the antigen-specific T cell repertoire (Ashwell et al., 1996). Interestingly, ADO has also been reported to interfere with the TCR-induced signaling pathways and negative selection via interfering with the $\mathrm{CD} 3 \zeta$ chain phosphorylation (Apasov et al., 2000). Thus ADO, similar to glucocorticoids and retinoids, might affect the TCR avidity thresholds in a dose dependent manner. And finally, development of $\mathrm{tT}_{\text {reg }}$ cells have been shown to be dependent on engulfing macrophage-derived TGF- $\beta$ (Konkel et al., 2014; Chen and Konkel, 2015). Interestingly, both retinoids (Mucida et al., 2007) and ADO (Ohta and Sitkovsky, 2014) promote the TGF- $\beta$-dependent development of $\mathrm{T}_{\text {reg }}$ cells in the periphery. In CD73/prostatic acid phosphatase double knock out mice, where the extracellular ADO levels are low, the $\mathrm{t}_{\text {reg }}$ cell production was found to be impaired (Yegutkin et al., 2014 ) indicating the involvement of $\mathrm{ADO}$ also in the $\mathrm{tT}_{\text {reg }}$ cell differentiation.

\section{EFFECT OF ADENOSINE ON THE ENGULFMENT-RELATED PROCESSES OF THE MACROPHAGE}

Apoptotic cells release find me signals for macrophages so that the macrophages could find them efficiently. In the thymic cortex the apoptosis sensitive DP thymocytes are in strong interaction with the cortical macrophages forming clusters with them (Rezzani et al., 2008). Thus, the removal of the constantly appearing apoptotic cells might not require chemotactic migration of macrophages. When, however, a large amount of DP thymocytes die, additional macrophages migrate through vessels into the thymus, and enter the cortical region, where most of the apoptosis takes place (Odaka and Mizouchi, 2002). In macrophages a purinergic autocrine signaling functions to amplify and translate chemotactic signals into directional motility (Kronlage et al., 2010). Upon sensing chemotactic signals, macrophages release ATP at the leading edge of the cell, which is then degraded to ADP, AMP, and ADO. Loss of either adenosine $A_{3} R$ or $A_{2 B} R$ receptor function blocks the 
chemotactic migration of macrophages toward the apoptotic cells (Joós et al., 2017). The involvement of AR subtype in the control of chemotactic navigation, however, might be macrophage type specific, since peritoneal tissue resident macrophages express both receptors at high levels, while in monocyte-derived macrophages the expression of the adenosine $\mathrm{A}_{2 \mathrm{~B}} \mathrm{R}$ dominates. In accordance, loss of $\mathrm{A}_{3}$ Rs affects the apoptotic cell removal in the peritoneal cavity, but has no effect on the thymic apoptotic cell removal in vivo (Joós et al., 2017). ADO has no effect on the phagocytosis of apoptotic cells (Köröskényi et al., 2011; Duró et al., 2014), but it might contribute to the apoptotic cell-induced upregulation of cell surface TG2 (Szondy et al., 2003; Rébé et al., 2009; Sarang et al., 2014) which acts as a phagocytosis coreceptor in macrophages (Tóth et al., 2009) and contributes to the activation of TGF- $\beta$ released in latent form (Nunes et al., 1997). ADO is also required to maintain the immunologically silent removal of apoptotic cells. In the absence of $\mathrm{A}_{2 \mathrm{~A}} \mathrm{R}$ signaling $\mathrm{KC}$ and macrophage inflammatory protein-2 neutrophil chemokines are released by engulfing macrophages (Köröskényi et al., 2011). During the engulfment of apoptotic cells several anti-inflammatory mechanisms are activated to prevent the production of pro-inflammatory cytokines (Trahtemberg and Mevorach, 2017). Many of them act via inhibiting nuclear factor kappa-light-chain-enhancer of activated $\mathrm{B}$ cells $(\mathrm{NF}-\kappa \mathrm{B})$ transcriptional activity which plays a key role in the induction of inflammatory cytokine genes (Baeuerle and Henkel, 1994), or via inducing the production of TGF- $\beta$ or IL-10 (Szondy et al., 2017). ADO signaling was also shown to interfere with the NF-кB function by inhibiting its nuclear translocation, DNA binding and transcriptional activity (Xia et al., 2000; Majumdar and Aggarwal, 2003; Lukashev et al., 2004) and to induce IL-10 (Németh et al., 2005). In addition, $A_{2 A} R$ signaling prevents nitrogen monoxide formation in engulfing macrophages (Köröskényi et al., 2011) and enhances the expression of dual specific phosphatase, which interferes the MAPK signaling pathways known to contribute also to the pro-inflammatory cytokine expression (Köröskényi et al., 2016).

\section{REFERENCES}

Alexandropoulos, K., and Danzi, N. M. (2012). Thymic epithelial cells: antigen presenting cells that regulate $\mathrm{T}$ cell repertoire and tolerance development. Immunol. Res. 54, 177-190. doi: 10.1007/s12026-0128301-y

Antonioli, L., Csóka, B., Fornai, M., Colucci, R., Kókai, E., Blandizzi, C., et al. (2014). Adenosine and inflammation: what's new on the horizon? Drug Discov. Today 19, 1051-1068. doi: 10.1016/j.drudis.2014.02.010

Antonioli, L., Pacher, P., Vizi, E. S., and Haskó, G. (2013). CD39 and CD73 in immunity and inflammation. Trends Mol. Med. 19, 355-367. doi: 10.1016/j. molmed.2013.03.005

Apasov, S., Chen, J. F., Smith, P., and Sitkovsky, M. (2000). A(2A) receptor dependent and $\mathrm{A}(2 \mathrm{~A})$ receptor independent effects of extracellular adenosine on murine thymocytes in conditions of adenosine deaminase deficiency. Blood 95, 3859-3867.

Armstrong, J. M., Chen, J. F., Schwarzschild, M. A., Apasov, S., Smith, P. T., Caldwell, C., et al. (2001). Gene dose effect reveals no Gs-coupled A2A adenosine receptor reserve in murine T-lymphocytes: studies of cells from A2A-receptor-gene-deficient mice. Biochem. J. 354, 123-130. doi: 10.1042/bj354 0123
$\mathrm{A}_{3} \mathrm{Rs}$, on the other hand, were found to promote apoptotic cell uptake-induced neutrophil chemoattractant formation (Duró et al., 2014). Since $A_{3}$ Rs are downregulated during engulfment, while the expression of $\mathrm{A}_{2 \mathrm{~A}} \mathrm{Rs}$ is induced, the immune silencing signaling of $\mathrm{ADO}$ acting via the upregulated $\mathrm{A}_{2 \mathrm{~A}}$ Rs dominate during phagocytosis of apoptotic cells.

\section{CONCLUSION}

Increasing evidence indicate that macrophages engulfing apoptotic cells respond to the chemotactic signals released by apoptotic cells, to the apoptotic cell engagement and to the apoptotic cell uptake with producing various molecules, such as ATP, IL-10, TGF- $\beta$, CO, prostaglandin $E_{2}$, retinoids, and also ADO. These molecules together regulate either the phagocytic activity of macrophages and/or contribute to the immunologically silent removal of apoptotic cells. However, they might play also additional roles in the maintenance of tissue homeostasis, and this role vary from tissue to tissue. The data presented in this review indicate that in the thymus ADO in an interplay with other engulfing macrophage-derived molecules might contribute to the thymocyte selection processes (Figure 1).

\section{AUTHOR CONTRIBUTIONS}

All authors listed have made a substantial, direct and intellectual contribution to the work, and approved it for publication.

\section{ACKNOWLEDGMENTS}

This study was supported by the National Research, Development and Innovation Office (124244) and by the GINOP-2.3.2-152016-00006 project (co-financed by the European Union and the European Regional Development Fund).

Ashwell, J. D., King, L. B., and Vacchio, M. S. (1996). Cross-talk between the $\mathrm{T}$ cell antigen receptor and the glucocorticoid receptor regulates thymocyte development. Stem Cells 14, 490-500. doi: 10.1002/stem.140490

Baeuerle, P. A., and Henkel, T. (1994). Function and activation of NF-kappa B in the immune system. Annu. Rev. Immunol. 12, 141-179. doi: 10.1146/annurev. iy.12.040194.001041

Benoist, C., and Mathis, D. (2012). Treg cells, life history, and diversity. Cold Spring Harb. Perspect. Biol. 4:a007021. doi: 10.1101/cshperspect.a007021

Bommhardt, U., Beyer, M., Hünig, T., and Reichardt, H. M. (2004). Molecular and cellular mechanisms of T cell development. Cell. Mol. Life Sci. 61, 263-280. doi: 10.1007/s00018-003-3224-3

Chechik, B. E., Schrader, W. P., and Minowada, J. (1981). An immunomorphologic study of adenosine deaminase distribution in human thymus tissue, normal lymphocytes, and hematopoietic cell lines. J. Immunol. 126, 1003-1007.

Chekeni, F. B., Elliott, M. R., Sandilos, J. K., Walk, S. F., Kinchen, J. M., Lazarowski, E. R., et al. (2010). Pannexin 1 channels mediate 'find-me' signal release and membrane permeability during apoptosis. Nature 467, 863-867. doi: 10.1038/ nature09413

Chen, J. F., Eltzschig, H. K., and Fredholm, B. B. (2013). Adenosine receptors as drug targets-what are the challenges? Nat. Rev. Drug Discov. 12, 265-286. doi: $10.1038 / \operatorname{nrd} 3955$ 
Chen, W., and Konkel, J. E. (2015). Development of thymic Foxp3(+) regulatory T cells: TGF- $\beta$ matters. Eur. J. Immunol. 45, 958-965. doi: 10.1002/eji.201444999

Cillie, Y., Deviller, P., and Beteuel, H. (1983). Guanylate cyclase activity of human lymphocytes from peripheral blood, thymus, and tonsils. A comparative study. Enzyme 129, 86-92. doi: 10.1159/000469612

da Rocha Lapa, F., Macedo, S. J. Jr., Cerutti, M. L., and Santos, A. R. (2014). "Pharmacology of Adenosine Receptors and Their Signaling Role in Immunity and Inflammation. in Pharmacology and Therapeutics, ed. S. J. T. Gowder (Rijeka: InTech), 85-130. doi: 10.5772/57206

Dubyak, G. R. (2012). Function without form: an ongoing search for maxi-anion channel proteins. Focus on "Maxi-anion channel and pannexin 1 hemichannel constitute separate pathways for swelling-induced ATP release in murine L929 fibrosarcoma cells". Am. J. Physiol. Cell Physiol. 303, C913-C915. doi: 10.1152/ ajpcell.00285.2012

Duró, E., Pallai, A., Köröskényi, K., Sarang, Z., and Szondy, Z. (2014). Adenosine A3 receptors negatively regulate the engulfment-dependent apoptotic cell suppression of inflammation. Immunol. Lett. 162, 292-301. doi: 10.1016/j.imlet. 2014.06.014

Dzhagalov, I., Chambon, P., and He, Y. W. (2007). Regulation of CD8+ $\mathrm{T}$ lymphocyte effector function and macrophage inflammatory cytokine production by retinoic acid receptor $\gamma$. J. Immunol. 178, 2113-2121. doi: 10.4049/jimmunol.178.4.2113

Eichin, D., Laurila, J. P., Jalkanen, S., and Salmi, M. (2015). CD73 Activity is dispensable for the polarization of M2 macrophages. PLOS ONE 10:e0134721. doi: 10.1371/journal.pone. 0134721

Eltzschig, H. K. (2009). Adenosine: an old drug newly discovered. Anesthesiology 111, 904-915. doi: 10.1097/ALN.0b013e3181b060f2

Esashi, E., Ito, H., Ishihara, K., Hirano, T., Koyasu, S., and Miyajima, A. (2004). Development of $\mathrm{CD} 4+$ macrophages from intrathymic $\mathrm{T}$ cell progenitors is induced by thymic epithelial cells. J. Immunol. 173, 4360-4367. doi: 10.4049/ jimmunol.173.7.4360

Fadok, V. A., Bratton, D. L., Konowal, A., Freed, P. W., Westcott, J. Y., and Henson, P. M. (1998). Macrophages that have ingested apoptotic cells in vitro inhibit proinflammatory cytokine production through autocrine/paracrine mechanisms involving TGF-beta, PGE2, and PAF. J. Clin. Invest. 101, 890-898. doi: $10.1172 /$ JCI1112

Fésüs, L., and Szondy, Z. (2005). Transglutaminase 2 in the balance of cell death and survival. FEBS Lett. 579, 3297-3302. doi: 10.1016/j.febslet.2005.03.063

Fredholm, B. B., IJzerman, A. P., Jacobson, K. A., Klotz, K. N., and Linden, J. (2001) International Union of Pharmacology. XXV. Nomenclature and classification of adenosine receptors. Pharmacol. Rev. 53, 527-552.

Garabuczi, É, Kiss, B., Felszeghy, S., Tsay, G. J., Fésüs, L., and Szondy, Z. (2013). Retinoids produced by macrophages engulfing apoptotic cells contribute to the appearance of transglutaminase 2 in apoptotic thymocytes. Amino Acids 44, 235-244. doi: 10.1007/s00726-011-1119-4

Gemsa, C., Woo, C. H., Fudenberg, H. H., and Schmid, R. (1973). Erythrocyte catabolism by macrophages in vitro. The effect of hydrocortisone on erythrophagocytosis and on the induction of heme oxygenase. J. Clin. Invest. 52, 812-822. doi: 10.1172/JCI107245

Gomez, P. E., Klapproth, K., Schulz, C., Busch, K., Azzoni, E., Crozet, L., et al. (2015). Tissue-resident macrophages originate from yolk-sac-derived erythromyeloid progenitors. Nature 518, 547-551. doi: 10.1038/nature13989

Hamad, M. (1997). The role of adenosine receptor engagement in murine fetal thymocyte development. APMIS 107, 896-902. doi: 10.1111/j.1699-0463.1999. tb01489.x

Haschemi, A., Wagner, O., Marculescu, R., Wegiel, B., Robson, S. C., Gagliani, N., et al. (2007). Cross-regulation of carbon monoxide and the adenosine A2A receptor in macrophages. J. Immunol. 178, 5921-5929. doi: 10.4049/jimmunol. 178.9.5921

Haskó, G., and Cronstein, B. N. (2004). Adenosine: an endogenous regulator of innate immunity. Trends Immunol. 25, 33-39. doi: 10.1016/j.it.2003.11.003

Haskó, G., Pacher, P., Deitch, E. A., and Vizi, E. S. (2007). Shaping of monocyte and macrophage function by adenosine receptors. Pharmacol. Ther. 113, 264-275. doi: 10.1016/j.pharmthera.2006.08.003

Haymaker, C. L., Guloglu, F. B., Cascio, J. A., Hardaway, J. C., Dhakal, M., Wan, X., et al. (2012). Bone marrow-derived IL-13R $\alpha 1$-positive thymic progenitors are restricted to the myeloid lineage. J. Immunol. 188, 3208-3216. doi: 10.4049/ jimmunol.1103316
Heine, P., Braun, N., Sévigny, J., Robson, S. C., Servos, J., and Zimmermann, H. (2001). The C-terminal cysteine-rich region dictates specific catalytic properties in chimeras of the ectonucleotidases NTPDase1 and NTPDase2. Eur. I. Biochem. 268, 364-373. doi: 10.1046/j.1432-1033.2001.01896.x

Hernandez, J. B., Newton, R. H., and Walsh, C. M. (2010). Life and death in the thymus - cell death signaling during T cell development. Curr. Opin. Cell Biol. 22, 865-871. doi: 10.1016/j.ceb.2010.08.003

Joós, G., Jákim, J., Kiss, B., Szamosi, R., Papp, T., Felszeghy, S., et al. (2017). Involvement of adenosine A3 receptors in the chemotactic navigation of macrophages towards apoptotic cells. Immunol. Lett. 183, 62-72. doi: 10.1016/ j.imlet.2017.02.002

Kisielow, P., and von Boehmer, H. (1995). Development and selection of T cells: facts and puzzles. Adv. Immunol. 58, 87-209.

Kiss, I., Oskolás, H., Tóth, R., Bouillet, P., Tóth, K., Fülöp, A., et al. (2006). Adenosine A2A receptor-mediated cell death of mouse thymocytes involves adenylate cyclase and Bim and is negatively regulated by Nur77. Eur. J. Immunol. 36, 1559-1571. doi: 10.1002/eji.200535334

Konkel, J. E., Jin, W., Abbatiello, B., Grainger, J. R., and Chen, W. (2014). Thymocyte apoptosis drives the intrathymic generation of regulatory $\mathrm{T}$ cells. Proc. Natl. Acad. Sci. U.S.A. 111, E465-E473. doi: 10.1073/pnas.132031 9111

Köröskényi, K., Duró, E., Pallai, A., Sarang, Z., Kloor, D., Ucker, D. S., et al. (2011). Involvement of adenosine A2A receptors in engulfment-dependent apoptotic cell suppression of inflammation. J. Immunol. 186, 7144-7155. doi: 10.4049/ jimmunol.1002284

Köröskényi, K., Kiss, B., and Szondy, Z. (2016). Adenosine A2A receptor signaling attenuates LPS-induced pro-inflammatory cytokine formation of mouse macrophages by inducing the expression of DUSP1. Biochim. Biophys. Acta 1863, 1461-1471. doi: 10.1016/j.bbamcr.2016.04.003

Kronlage, M., Song, J., Sorokin, L., Isfort, K., Schwerdtle, T., Leipziger, J., et al. (2010). Autocrine purinergic receptor signaling is essential for macrophage chemotaxis. Sci. Signal. 3:ra555. doi: 10.1126/scisignal.2000588

Levéen, P., Carlsén, M., Makowska, A., Oddsson, S., Larsson, J., Goumans, M. J., et al. (2005). TGF-beta type II receptor-deficient thymocytes develop normally but demonstrate increased CD8+ proliferation in vivo. Blood 106, 4234-4240. doi: 10.1182/blood-2005-05-1871

Liu, H., and Xia, Y. J. (2015). Beneficial and detrimental role of adenosine signaling in diseases and therapy. J. Appl. Physiol. 119, 1173-1182. doi: 10.1152/ japplphysiol.00350.2015

Liu, Y., Zhang, P., Li, J., Kulkarni, A. B., Perruche, S., and Chen, W. (2008). A critical function for TGF-beta signaling in the development of natural CD4+CD25+Foxp3+ regulatory T cells. Nat. Immunol. 9, 632-640. doi: $10.1038 /$ ni. 1607

Lukashev, D. E., Ohta, A., Apasov, S., Chen, J. F., and Sitkovsky, M. (2004). Cutting edge: physiological attenuation of proinflammatory transcription by the Gs protein-coupled A2a adenosine receptor in vivo. J. Immunol. 173, 21-24. doi: 10.4049/jimmunol.173.1.21

Lukashev, D. E., Smith, P. T., Caldwell, C. C., Ohta, A., Apasov, S. G., and Sitkovsky, M. V. (2003). Analysis of A2a receptor-deficient mice reveals no significant compensatory increases in the expression of $\mathrm{A} 2 \mathrm{~b}, \mathrm{~A} 1$, and $\mathrm{A} 3$ adenosine receptors in lymphoid organs. Biochem. Pharmacol. 65, 2081-2090. doi: $10.1016 /$ S0006-2952(03)00158-8

Ma, D. D., Sylwestrowicz, T. A., Granger, S., Massaia, M., Franks, R., Janossy, G., et al. (1982). Distribution of terminal deoxynucleotidyl transferase and purine degradative and synthetic enzymes in subpopulations of human thymocytes. J. Immunol. 129, 1430-1435.

Majumdar, S., and Aggarwal, B. B. (2003). Adenosine suppresses activation of nuclear factor- $\mathrm{\kappa B}$ selectively induced by tumor necrosis factor in different cell types. Oncogene 22, 1206-1218. doi: 10.1038/sj.onc.1206184

McConkey, D. J., Orrenius, S., and Jondal, M. (1990). Agents that elevate cAMP stimulate DNA fragmentation in thymocytes. J. Immunol. 145, 1227-1230.

McConkey, D. J., Orrenius, S., Okret, S., and Jondal, M. (1993). Cyclic AMP potentiates glucocorticoid-induced endogenous endonuclease activation in thymocytes. FASEB J. 7, 580-585.

Moran, A. E., Holzapfel, K. L., Xing, Y., Cunningham, R. L., Maltzman, J. S., Punt, J., et al. (2011). T cell receptor signal strength in Treg and iNKT cell development demonstrated by a novel fluorescent reporter mouse. J. Exp. Med. 208, 1279-1289. doi: 10.1084/jem.20110308 
Mucida, D., Park, Y., Kim, G., Turovskaya, O., Scott, I., Kronenberg, M., et al. (2007). Reciprocal TH17 and regulatory T cell differentiation mediated by retinoic acid. Science 317, 256-260. doi: 10.1126/science.1145697

Németh, Z. H., Lutz, C. S., Csóka, B., Deitch, E. A., Leibovich, S. J., Gause, W. C., et al. (2005). Adenosine augments IL-10 production by macrophages through an A2B receptor-mediated posttranscriptional mechanism. J. Immunol. 175, 8260-8270. doi: 10.4049/jimmunol.175.12.8260

Nicholson, C. D., and Wilke, R. (1989). 8-phenyltheophylline as an inhibitor of cyclic AMP hydrolysis by cyclic nucleotide phosphodiesterase. J. Auton. Pharmacol. 9, 159-165. doi: 10.1111/j.1474-8673.1989.tb00207.x

Nishiura, H., Shibuya, Y., and Yamamoto, T. (1998). S19 ribosomal protein crosslinked dimer causes monocyte-predominant infiltration by means of molecular mimicry to complement C5a. Lab. Invest. 78, 1615-1623.

Nunes, I., Gleizes, P. E., Metz, C. N., and Rifkin, D. B. (1997). Latent transforming growth factor-beta binding protein domains involved in activation and transglutaminase-dependent cross-linking of latent transforming growth factor-beta. J. Cell Biol. 136, 1151-1163. doi: 10.1083/jcb.136.5.1151

Odaka, C. M., and Mizouchi, T. (2002). Macrophages are involved in DNA degradation of apoptotic cells in murine thymus after administration of hydrocortisone. Cell Death. Differ. 9, 104-112. doi: 10.1038/sj.cdd. 4400941

Ohta, A., and Sitkovsky, M. (2014). Extracellular adenosine-mediated modulation of regulatory T cells. Front. Immunol. 5:304. doi: 10.3389/fimmu.2014.00304

Park, J., and Gupta, R. S. (2012). "Adenosine Metabolism, Adenosine Kinase, and Evolution, Adenosine," in Adenosine, eds S. Masino and D. Boison (New York, NY: Springer), 23-54.

Petersen, C. B., Nygård, A. B., Viuff, B., Fredholm, M., Aasted, B., and Salomonsen, J. (2007). Porcine ecto-nucleotide pyrophosphatase/ phosphodiesterase 1 (NPP1/CD203a): cloning, transcription, expression, mapping, and identification of an NPP1/CD203a epitope for swine workshop cluster 9 (SWC9) monoclonal antibodies. Dev. Comp. Immunol. 31, 618-631. doi: 10.1016/j.dci.2006.08.012

Petrie, H. T., and Zuniga-Pflucker, J. C. (2007). Zoned out: functional mapping of stromal signaling microenvironments in the thymus. Annu. Rev. Immunol. 25, 649-679. doi: 10.1146/annurev.immunol.23.021704.115715

Piredda, L., Amendola, A., Colizzi, V., Davies, P. J., Farrace, M. G., Fraziano, M., et al. (1997). Lack of 'tissue' transglutaminase protein cross-linking leads to leakage of macromolecules from dying cells: relationship to development of autoimmunity in MRLIpr/Ipr mice. Cell Death Differ. 4, 463-472. doi: 10.1038/ sj.cdd. 4400267

Ramakers, B. P., Riksen, N. P., van der Hoeven, J. G., Smits, P., and Pickkers, P. (2011). Modulation of innate immunity by adenosine receptor stimulation. Shock 36, 208-215. doi: 10.1097/SHK.0b013e318225aee4

Rébé, C., Raveneau, M., Chevriaux, A., Lakomy, D., Sberna, A. L., Costa, A., et al. (2009). Induction of transglutaminase 2 by a liver $\mathrm{X}$ receptor/retinoic acid receptor alpha pathway increases the clearance of apoptotic cells by human macrophages. Circ. Res. 105, 393-401. doi: 10.1161/CIRCRESAHA.109. 201855

Resta, R., Hooker, S. W., Laurent, A. B., Jamshedur Rahman, S. M., Franklin, M., Knudsen, T. B., et al. (1997). Insights into thymic purine metabolism. J. Clin. Invest. 99, 676-683. doi: 10.1172/JCI119211

Resta, R., and Thompson, L. F. (1997). SCID: the role of adenosine deaminase deficiency. Immunol. Today 18, 371-374. doi: 10.1016/S0167-5699(97) 01047-5

Resta, R., Yamashita, Y., and Thompson, L. F. (1998). Ecto-enzyme and signaling functions of lymphocyte CD73. Immunol. Rev. 161, 95-109. doi: 10.1111/j. 1600-065X.1998.tb01574.x

Rezzani, R., Bonomini, F., and Rodella, L. F. (2008). Histochemical and molecular overview of the thymus as site for T-cells development. Prog. Histochem. Cytochem. 43, 73-120. doi: 10.1016/j.proghi.2008.03.001

Sandberg, G. (1983). Regulation of thymocyte proliferation by endogenous adenosine and adenosine deaminase. Int. J. Immunopharmacol. 5, 259-265. doi: 10.1016/0192-0561(83)90027-9

Sandilos, J. K., Chiu, Y. H., Chekeni, F. B., Armstrong, A. J., Walk, S. F., Ravichandran, K. S., et al. (2012). Pannexin 1, an ATP release channel, is activated by caspase cleavage of its pore-associated C-terminal autoinhibitory region. J. Biol. Chem. 287, 11303-11311. doi: 10.1074/jbc.M111. 323378
Sándor, K., Daniel, B., Kiss, B., Kovács, F., and Szondy, Z. (2016). Transcriptional control of transglutaminase 2 expression in mouse apoptotic thymocytes. Biochim. Biophys. Acta 1859, 964-974. doi: 10.1016/j.bbagrm.2016. 05.011

Sándor, K., Pallai, A., Duró, E., Legendre, P., Couillin, I., Sághy, T., et al. (2017). Adenosine produced from adenine nucleotides through an interaction between apoptotic cells and engulfing macrophages contributes to the appearance of transglutaminase 2 in dying thymocytes. Amino Acids 49, 671-681. doi: 10.1007/s00726-016-2257-5

Sarang, Z., Garabuczi, É, Joós, G., Kiss, B., Tóth, K., Rühl, R., et al. (2013). Macrophages engulfing apoptotic thymocytes produce retinoids to promote selection, differentiation, removal and replacement of double positive thymocytes. Immunobiology 218, 1354-1360. doi: 10.1016/j.imbio.2013. 06.009

Sarang, Z., Joós, G., Garabuczi, E., Rühl, R., Gregory, C. D., and Szondy, Z. (2014). Macrophages engulfing apoptotic cells produce non-classical retinoids to enhance their phagocytic capacity. J. Immunol. 192, 5730-5738. doi: 10.4049/ jimmunol.1400284

Sarang, Z., Mádi, A., Koy, C., Varga, S., Glocker, M. O., Ucker, D. S., et al. (2007). Tissue transglutaminase (TG2) facilitates phosphatidylserine exposure and calpain activity in calcium-induced death of erythrocytes. Cell Death Differ. 14, 1842-1844. doi: 10.1038/sj.cdd.4402193

Stefan, C., Jansen, S., and Bollen, M. (2006). Modulation of purinergic signaling by NPP-type ectophosphodiesterases. Purinergic Signal. 2, 361-370. doi: 10.1007/ s11302-005-5303-4

Streitová, D., Sefc, L., Savvulidi, F., Pospísil, M., Holá, J., and Hofer, M. (2010). Adenosine $\mathrm{A}(1), \mathrm{A}(2 \mathrm{a}), \mathrm{A}(2 \mathrm{~b})$, and $\mathrm{A}(3)$ receptors in hematopoiesis. 1 . Expression of receptor mRNA in four mouse hematopoietic precursor cells. Physiol. Res. 59, 133-137.

Surh, C. D., and Sprent, J. (1994). T-cell apoptosis detected in situ during positive and negative selection in the thymus. Nature 372, 100-103. doi: 10.1038/ $372100 \mathrm{a} 0$

Suzuki, K., Tadakuma, T., and Kizaki, H. (1991). Modulation of thymocyte apoptosis by isoproterenol and prostaglandin E2. Cell. Immunol. 134, 235-240. doi: 10.1016/0008-8749(91)90346-D

Szegezdi, E., Kiss, I., Simon, A., Blaskó, B., Reichert, U., Michel, S., et al. (2003). Ligation of retinoic acid receptor alpha regulates negative selection of thymocytes by inhibiting both DNA binding of nur77 and synthesis of bim. J. Immunol. 170, 3588-3594. doi: 10.4049/jimmunol.170.7.3577

Szegezdi, E., Szondy, Z., Nagy, L., Nemes, Z., Friis, R. R., Davies, P. J., et al. (2000). Apoptosis-linked in vivo regulation of the tissue transglutaminase gene promoter. Cell Death Differ. 7, 1225-1233. doi: 10.1038/sj.cdd.44 00751

Szondy, Z. (1994). Adenosine stimulates DNA fragmentation in human thymocytes by $\mathrm{Ca}(2+)$-mediated mechanisms. Biochem. J. 304( $\mathrm{Pt} 3)$, $877-885$.

Szondy, Z., Garabuczi, E., Tóth, K., Kiss, B., and Köröskényi, K. (2012). Thymocyte death by neglect: contribution of engulfing macrophages. Eur. J. Immunol. 42, 1662-1667. doi: 10.1002/eji.201142338

Szondy, Z., Reichert, U., Bernardon, J. M., Michel, S., Tóth, R., Ancian, P., et al. (1997). Induction of apoptosis by retinoids and retinoic acid receptor gammaselective compounds in mouse thymocytes through a novel apoptosis pathway. Mol. Pharmacol. 51, 972-982.

Szondy, Z., Reichert, U., Bernardon, J. M., Michel, S., Tóth, R., Karászi, E., et al. (1998). Inhibition of activation-induced apoptosis of thymocytes by all-transand 9-cis-retinoic acid is mediated via retinoic acid receptor alpha. Biochem. J. 331, 767-774. doi: 10.1042/bj3310767

Szondy, Z., Sarang, Z., Kiss, B., Garabuczi, É, and Köröskényi, K. (2017). Antiinflammatory mechanisms triggered by apoptotic cells during their clearance. Front. Immunol. 8:909. doi: 10.3389/fimmu.2017.00909

Szondy, Z., Sarang, Z., Molnar, P., Nemeth, T., Piacentini, M., Mastroberardino, P. G., et al. (2003). Transglutaminase 2-/- mice reveal a phagocytosis-associated crosstalk between macrophages and apoptotic cells. Proc. Natl. Acad. Sci. U.S.A. 100, 7812-7817. doi: 10.1073/pnas.0832466100

Tóth, B., Garabuczi, E., Sarang, Z., Vereb, G., Vámosi, G., Aeschlimann, D., et al. (2009). Transglutaminase 2 is needed for the formation of an efficient phagocyte portal in macrophages engulfing apoptotic cells. J. Immunol. 182, 2084-2092. doi: 10.4049/jimmunol.0803444 
Trahtemberg, U., and Mevorach, D. (2017). Apoptotic cells induced signaling for immune homeostasis in macrophages and dendritic cells. Front. Immunol. 8:1356. doi: 10.3389/fimmu.2017.01356

Tsukimoto, M., Maehata, M., Harada, H., Ikari, A., Takagi, K., and Degawa, M. (2006). P2X7 receptor-dependent cell death is modulated during murine $\mathrm{T}$ cell maturation and mediated by dual signaling pathways. J. Immunol. 177, 2842-2850. doi: 10.4049/jimmunol.177.5.2842

Xia, D., Wang, F., and Parmely, M. J. (2000). Inhibition of nuclear factor-kappab activation in mouse macrophages and the RAW264.7 cell line by a synthetic adenyl carbocyclic nucleoside. Biochem. Pharmacol. 60, 717-727. doi: 10.1016/ S0006-2952(00)00367-1

Yamaguchi, H., Maruyama, T., Urade, Y., and Nagata, S. (2014). Immunosuppression via adenosine receptor activation by adenosine monophosphate released from apoptotic cells. Elife 3:e02172. doi: $10.7554 /$ eLife. 02172
Yegutkin, G. G., Auvinen, K., Karikoski, M., Rantakari, P., Gerke, H., Elima, K., et al. (2014). Consequences of the lack of CD73 and prostatic acid phosphatase in the lymphoid organs. Mediators Inflamm. 2014:485743. doi: 10.1155/2014/ 485743

Conflict of Interest Statement: The authors declare that the research was conducted in the absence of any commercial or financial relationships that could be construed as a potential conflict of interest.

Copyright (C) 2017 Köröskényi, Joós and Szondy. This is an open-access article distributed under the terms of the Creative Commons Attribution License (CC BY).

The use, distribution or reproduction in other forums is permitted, provided the original author(s) or licensor are credited and that the original publication in this journal is cited, in accordance with accepted academic practice. No use, distribution or reproduction is permitted which does not comply with these terms. 